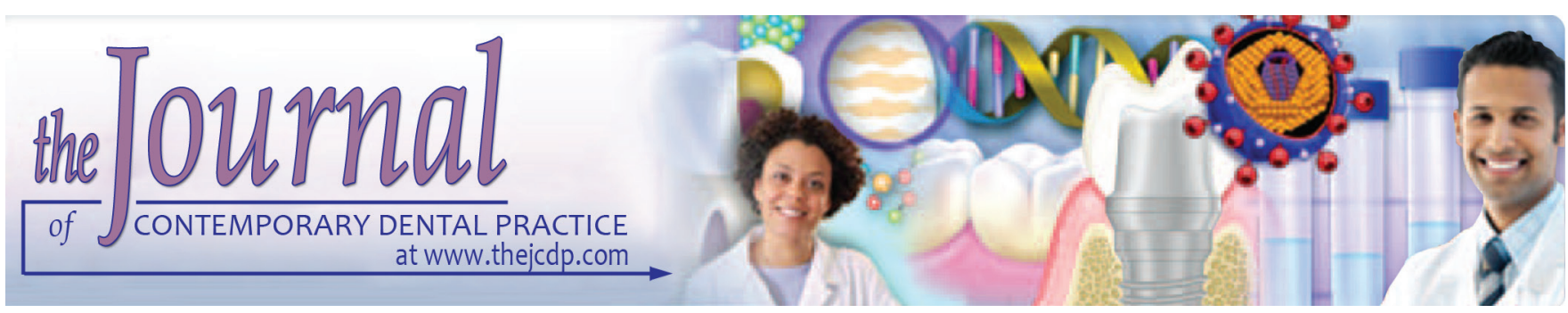

\title{
Oral Lesions found in a Dental School in Southern Brazil
}

\author{
${ }^{1}$ Letícia C Dogenski, ${ }^{2}$ Ana P Farina, ${ }^{3}$ Maria SS Linden, ${ }^{4}$ Micheline S Trentin, ${ }^{5}$ Daniela C Miyagaki, ${ }^{6}$ João P De Carli
}

\begin{abstract}
Objective: This study aimed to perform an epidemiological survey of the cases of oral lesions diagnosed in a Brazilian dental school.

Materials and methods: An epidemiological survey was carried out at the Faculty of Dentistry of the University of Passo Fundo (FOUPF), Rio Grande do Sul, Brazil, between March 2015 and June 2017, characterizing the patients in terms of gender, age, and ethnicity. A total of 3,200 records were evaluated, from which 716 presented information on oral lesions diagnosed and treated at the clinics of the FOUPF. The data were evaluated by descriptive statistics of frequency.
\end{abstract}

Results: The most frequent change was the coated tongue $(13.83 \%)$. The majority of the patients were female $(56 \%)$, white $(31.57 \%)$, in the sixth decade of life $(21.65 \%)$. Regarding the classification of lesions, the most frequent group was developmental changes (25\%).

Conclusion: It is considered that the sample studied presented a significant index of oral lesions and normality changes, considering that $716(22.38 \%)$ patients studied showed some type of change in the oral cavity.

Clinical significance: The sample studied presents peculiar characteristics regarding the number of oral lesions/conditions diagnosed. It is also considered that Schools of Dentistry are valuable environments for carrying out epidemiological surveys in stomatology, providing the diagnostic exercise, as long as the students are stimulated for this purpose.

\footnotetext{
${ }^{1,6}$ Department of Oral Medicine, Faculty of Dentistry, University of Passo Fundo (UPF), Passo Fundo, Rio Grande do Sul, Brazil

${ }^{2}$ Department of Restorative Dentistry, Faculty of Dentistry University of Passo Fundo (UPF), Passo Fundo, Rio Grande do Sul, Brazil

${ }^{3,4}$ Department of Implantology, Faculty of Dentistry, University of Passo Fundo (UPF), Passo Fundo, Rio Grande do Sul, Brazil

${ }^{5}$ Department of Endodontics, Faculty of Dentistry, University of Passo Fundo (UPF), Passo Fundo, Rio Grande do Sul, Brazil

Corresponding Author: João P De Carli, Av. Brasil, 239, sala. 501. Centro, Passo Fundo, Rio Grande do Sul 99010-010, Brazil Phone: +5554991123079, e-mail: joaodecarli@upf.br
}

Keywords: Diagnosis, Epidemiology, Oral lesions, Stomatology, Treatment.

How to cite this article: Dogenski LC, Farina AP, Linden MSS, Trentin MS, Miyagaki DC, De Carli JP. Oral Lesions found in a Dental School in Southern Brazil. J Contemp Dent Pract 2018;19(9):1037-1041.

\section{Source of support: Nil}

\section{Conflict of interest: None}

\section{INTRODUCTION}

Oral diseases and their sequelae are highly frequent in stomatology clinics and may represent serious social and economic consequences. Risk and protection factors may have an unequal impact on social strata, with deleterious or salutary effects that affect the population in a heterogeneous way and increase health inequalities. ${ }^{1}$ Hence, due to the various sources of information that may be considered in patient anamnesis, the process for reaching a diagnosis is not always simple.

According to Ali et al, ${ }^{2}$ in the face of an oral and maxillofacial change, the conduct for the health professional to provide a correct diagnosis is to associate the anamnestic examination with a thorough physical assessment in order to collect all possible information about the lesion found. Such data will not only be significant to assess the etiopathogenesis of the change, but also to assist the professional in determining an accurate diagnosis for the treatment and preservation of the patient. When necessary, the anamnestic and physical examinations may be associated with complementary ones, increasing diagnostic acuity.

One of the main obstacles for health professionals in the case of oral lesions is establishing an accurate diagnosis, due to the high number of differential diagnoses that such conditions may present. Aided by prevalence studies, it is feasible to reduce the number of differential diagnoses, identifying the frequency of injuries for each region, also considering variables, such as age group, 
Table 1: Distribution of the sample studied according to gender, age group, and ethnicity

\begin{tabular}{|c|c|c|c|c|c|c|c|}
\hline \multirow[b]{3}{*}{ Age group (years) } & \multirow[b]{3}{*}{$n$} & \multirow[b]{3}{*}{$\%$} & \multirow{2}{*}{\multicolumn{2}{|c|}{ Gender }} & \multicolumn{3}{|c|}{ Ethnicity } \\
\hline & & & & & \multicolumn{3}{|c|}{ Not specified $=454$ (63.4\%) } \\
\hline & & & Female & Male & White & Black & Brown \\
\hline Under 10 & 2 & 0.28 & 0 & 2 & 0 & 0 & 0 \\
\hline $10-19$ & 61 & 8.51 & 32 & 29 & 16 & 0 & 5 \\
\hline $20-29$ & 117 & 16.34 & 57 & 59 & 38 & 1 & 2 \\
\hline $30-39$ & 102 & 14.25 & 62 & 41 & 38 & 0 & 3 \\
\hline $40-49$ & 118 & 16.49 & 73 & 46 & 40 & 7 & 6 \\
\hline $50-59$ & 155 & 21.65 & 87 & 68 & 44 & 1 & 2 \\
\hline $60-69$ & 125 & 17.45 & 74 & 50 & 40 & 0 & 8 \\
\hline $70-79$ & 31 & 4.33 & 15 & 16 & 10 & 0 & 0 \\
\hline 80-89 & 5 & 0.7 & 1 & 4 & 0 & 0 & 1 \\
\hline Over 90 & 0 & 0 & 0 & 0 & 0 & 0 & 0 \\
\hline Total & 716 & 100 & 401 & 315 & 226 & 9 & 27 \\
\hline
\end{tabular}

ethnicity, and gender. These epidemiological surveys are required for both determining the prevalence of oral lesions and diseases and assessing treatment needs. When health professionals are aware of the data obtained, they can plan and perform actions for the deficiencies observed, aiming at higher service effectiveness and allowing comparisons on the most prevalent cases, in different periods of time and regions. It is essential that national surveys are performed periodically and regularly so as to understand the epidemiological reality of the population based on periodic and sequence cross-sections. ${ }^{3}$

Based on the above considerations, this study aimed to perform an epidemiological survey of the cases of oral lesions diagnosed at FOUPF, between March 2015 and June 2017, characterizing patients in relation to gender, ethnicity, and age.

\section{MATERIALS AND METHODS}

This project was approved by the Research Ethics Committee of the University of Passo Fundo (approval protocol number 158.990). An epidemiological survey was performed based on the analysis of data from the dental records of patients assisted at the FOUPF, Rio Grande do Sul, Brazil; the records were filed in the Examination, Screening, and Urgency Sector for the period between March 2015 and June 2017. The data collected were recorded in a spreadsheet developed in Microsoft Excel ${ }^{\mathrm{TM}}$ software containing the following variables: Record number, gender, age, ethnicity, diagnostic hypothesis, treatment, histopathological report (when applicable), and patient's city of origin. The data were analyzed by descriptive statistics of frequency.

\section{RESULTS}

A total of 3,200 dental records were analyzed, from which 716 lesions and/or normality changes were found.
Regarding gender, women were the most affected, with 401 cases (56\%), and 315 cases $(44 \%)$ were males. As for ethnicity, $31.57 \%$ of the patients were white (226 cases), $3.77 \%$ were brown (27 cases), and $1.26 \%$ were black (9 cases), but $63.4 \%$ of the dental records did not contain this information about the patient. Age ranged from 5 to 86 years and the majority of patients were in the sixth decade of life (between 50 and 59 years) (Table 1).

We found 82 different diagnostic hypotheses in this study. The most frequent changes were coated tongue $(13.83 \%)$, linea alba $(9.22 \%)$, fistula $(7.82 \%)$, irritation fibroma $(5.17 \%)$, and pseudomembranous candidiasis (5.03\%) (Table 2). Regarding the classification groups

Table 2: Distribution of the sample studied according to the most prevalent diagnostic hypotheses

\begin{tabular}{lll}
\hline Diagnostic hypothesis & $n$ & $\%$ \\
\hline Coated tongue & 99 & 13.83 \\
Linea alba & 66 & 9.22 \\
Fistula & 56 & 7.82 \\
Irritation fibroma & 37 & 5.17 \\
Pseudomembranous candidiasis & 36 & 5.03 \\
Fissured tongue & 26 & 3.63 \\
Geographic tongue & 26 & 3.63 \\
Torus & 26 & 3.63 \\
Inflammatory fibrous hyperplasia & 25 & 3.49 \\
Pericoronitis & 22 & 3.07 \\
Fordyce's condition & 20 & 2.79 \\
Actinic cheilitis & 18 & 2.51 \\
Traumatic ulcer & 16 & 2.23 \\
Erythematous candidiasis & 15 & 2.09 \\
Chronic biting of oral mucosa & 13 & 1.82 \\
Papilloma & 13 & 1.82 \\
Frictional hyperkeratosis & 10 & 1.4 \\
Mouth ulcers & 9 & 1.26 \\
Supernumerary teeth & 9 & 1.26 \\
Hemangioma & 9 & 1.26 \\
Other hypotheses & 165 & 23.04 \\
\hline Total & 716 & 100 \\
\hline
\end{tabular}


Oral Lesions found in a Dental School in Southern Brazil

Table 3: Distribution of the sample studied according to the classification of the lesions

\begin{tabular}{lll}
\hline Classification & $n$ & $\%$ \\
\hline Developmental changes & 179 & 25 \\
White lesions & 177 & 24.72 \\
Hyperplastic proliferative lesions & 104 & 14.52 \\
Vesiculobullous lesions & 85 & 11.87 \\
Red lesions & 39 & 5.45 \\
Ulcerated lesions & 38 & 5.31 \\
Benign neoplasms & 23 & 3.21 \\
Odontogenic cysts and tumors & 16 & 2.23 \\
Pigmented lesions & 15 & 2.09 \\
Mucus retention & 12 & 1.68 \\
Nonodontogenic cysts and tumors & 11 & 1.54 \\
Malignant neoplasms & 9 & 1.26 \\
Fissured lesions and fractures & 4 & 0.56 \\
Syndromes with oral manifestations & 4 & 0.56 \\
\hline Total & 716 & 100 \\
\hline
\end{tabular}

for the lesions, developmental changes were the most frequent $(25 \%)$, followed by white lesions $(24.72 \%)$, hyperplastic proliferative lesions $(14.52 \%)$, vesiculobullous lesions ( $11.87 \%$ each), and red lesions ( $5.45 \%)$. Table 3 shows these values.

As to the treatment established for the lesions found, surgical treatment was the most prevalent, followed by the prescription of medications, endodontics, and laser therapy. Many of the normality changes found did not require treatment and some presented more than one treatment option, resulting in 723 treatments. However, a great portion of the files did not contain this information about the cases, as Table 4 presents.

\section{DISCUSSION}

Cross-sectional studies, also known as sectional or prevalence studies, surveys, or epidemiological surveys are important tools in the field of health surveillance. ${ }^{3}$ The research on oral lesions in different regions of Brazil characterizes the populations and identifies the needs of each one of them, facilitating the development of health promotion actions, as well as prevention and treatment. Health policies should be evaluated not only by their overall effect on collective health, but also by the outcome of their interventions on the preexisting framework of health inequalities. ${ }^{1}$

The present study evaluated 3,200 dental records filed in the Examination, Screening, and Urgency Sector of FOUPF, Rio Grande do Sul, Brazil, in search of the lesions most frequently presented by patients assisted at the clinics of the FOUPF, considering variables, such as gender, ethnicity, and age. This survey resulted in 716 records of either oral lesions or normality changes.

Regarding gender, women were the most affected, with 401 cases (56\%). This result corroborates the study
Table 4: Distribution of the sample studied according to the treatment established

\begin{tabular}{lll}
\hline Treatment & $n$ & $\%$ \\
\hline Not specified & 270 & 37.34 \\
Not required & 188 & 26 \\
Excisional biopsy & 80 & 11.07 \\
Endodontics & 55 & 7.61 \\
Prescription of medications (nystatin, daktarin, & 35 & 4.84 \\
decadron, acyclovir, zinc oxide, and & & \\
dexamethasone) & & \\
Laser therapy & 20 & 2.77 \\
Exodontia & 16 & 2.21 \\
Use of lip moisturizer & 12 & 1.66 \\
Oral hygiene instruction & 9 & 1.24 \\
Incisional biopsy & 8 & 1.11 \\
Referrals & 8 & 1.11 \\
Other treatments & 22 & 3.04 \\
\hline Total & 723 & 100 \\
\hline
\end{tabular}

by Tortorici et $\mathrm{al}^{4}{ }^{4}$ which analyzed a total of 2,539 patients assisted in the courses of Surgery, Oncology, and Stomatology of the University of Palermo, from January 2012 to February 2015, and verified that 52\% (1,330 cases) of the sample consisted of women. Maturana-Ramírez et al ${ }^{5}$ exposed a similar situation in a retrospective study of 1,149 biopsies with histopathological diagnosis of reactive hyperplastic lesions, performed from 2000 to 2011 and registered in the Department of Pathology and Oral Medicine of the School of Dentistry of the University of Chile. In their study, a rate of $72.2 \%$ (629 cases) was found for the female gender.

One possible explanation for this prevalence is that women seek health services the most. However, other causes may be considered for this higher incidence of lesions in a given group and some changes may be associated with factors common to one gender. The oral mucosa is sensitive to many systemic changes in the body, such as physiological, metabolic, hormonal, or chemical changes. ${ }^{6}$ For instance, the pyogenic granuloma, which etiology has been associated with hormonal changes due to the vascular effects of female hormones. According to Jafarzadeh et $\mathrm{al}_{1}{ }^{7}$ the development of this lesion, especially in pregnant women, suggests an existing relationship between its onset and hormonal conditions. In the present study, five cases of pyogenic granuloma were found, with four occurrences in women.

On the contrary, according to Antunes et $\mathrm{al}^{8}$, the incidence of oral cancer among men in Brazil (almost 11 per $100,000)$ was estimated as the third highest in the world. In 2008, as mentioned in the study by Borges et al, ${ }^{9}$ the National Cancer Institute estimated 3,000 cases of oral cancer in men and 1,140 cases in women living in Brazilian capitals. In the present study, seven diagnostic hypotheses of squamous cell carcinoma were found, six of which 
occurred in men, as well as a single case of diagnosed carcinoma in situ. Antunes et $\mathrm{al}^{8}$ estimated the mortality rates of oral cancer in the city of São Paulo between 2003 and 2009, stating that in Porto Alegre (southern Brazil), from 2000 to 2004, there were 670 new cases of cancer, while in São Paulo, from 2000 to 2005, 6,839 new cases were recorded for the same anatomical areas.

As for age, the sixth decade of life was the most affected, with 155 cases $(21.65 \%)$. Several studies relate patients over 60 years as the most susceptible to the development of oral lesions and most surveys show the fifth and sixth decades of life as the most frequent. Studying the prevalence of oral mucosal lesions in 126 patients over 60 years in the Diocesan Bishop Polyclinic of Valparaíso, between 2006 and 2009, Cueto et $\mathrm{al}^{10}$ found that $67.5 \%$ of the patients presented some type of change. According to Saintrain et al, ${ }^{11}$ this may occur because age may be associated with the appearance of systemic diseases, the presence of deleterious habits, the use of sometimes illadapted prostheses, parafunctional habits, and quantity and quality of saliva, which facilitate the appearance of oral pathologies.

Regarding ethnicity, $31.57 \%$ of the patients in the present study were white, $3.77 \%$ were brown, and $1.26 \%$ were black. The high index of oral lesions in white individuals has appeared in several epidemiological studies. According to Carvalho et $\mathrm{al}^{12}$ the high rate of lesions in white patients may occur because in Brazil, these individuals have the most access to dental treatment. An evaluation of school-aged children indicated that black and brown patients had less access to dental care than white ones, and a lower proportion of their teeth was restored. ${ }^{1}$ On the contrary, when evaluating the data from a national epidemiological survey promoted by the Brazilian Health Authority, between 2000 and 2004, Peres et $\mathrm{al}^{13}$ found a greater tendency of periodontal disease among black and brown patients. The main obstacle identified in the present study regarding ethnicity was that most of the dental records did not present this information about the patients $(63.4 \%)$, showing some negligence from the examiner in relation to variables that are important for the pathological analysis.

The five most prevalent lesions presented by patients treated at the FOUPF between March 2015 and June 2017 were: Coated tongue (13.83\%), linea alba (9.22\%), fistula $(7.82 \%)$, irritation fibroma $(5.17 \%)$, and pseudomembranous candidiasis $(5.03 \%)$, contrary to the study by Tortorici et al, ${ }^{4}$ which found hairy tongue (16.7\%) as the most frequent lesion. In the present study, a single case of hairy tongue $(0.13 \%)$ was found.

Epidemiological studies conducted in different parts of the world have found tongue lesions to be among the most common changes of the oral mucosa. Corroborating this, Vieira-Andrade et al $^{14}$ affirmed that coated tongue $(12.5 \%)$ and fissured tongue $(10.0 \%)$ are among the seven most prevalent changes identified. The same was verified in a study by Patil et al, ${ }^{15}$ which examined the presence of various tongue lesions in 4,926 patients attending the School of Oral Medicine and Radiology, Jodhpur Dental College General Hospital, between October 2010 and September 2012. The most common lesion diagnosed in the study sample was coated tongue (28.0\%).

The most prevalent lesion classification was developmental changes (25\%), which are normality changes that, in most cases, do not require treatment. The second most prevalent group was white lesions (24.72\%), which are characterized by the presence of changes, such as frictional hyperkeratosis, nicotine stomatitis, lichen planus, coated tongue, and pseudomembranous candidiasis. According to some authors, ${ }^{11,16}$ tobacco use is strongly associated with the appearance of intraoral white lesions, and the consumption of tobacco along with alcoholic beverages may be associated with periods of exacerbation of lichen planus, although its etiology has not been fully explained.

The next most prevalent group is the hyperplastic proliferative lesions (14.52\%). This group of lesions, which main characteristic is tissue proliferation usually of an inflammatory nature, commonly occurs in the oral mucosa. Among the lesions in this group are inflammatory fibrous hyperplasia, irritation fibroma, pyogenic granuloma, peripheral cemento-ossifying fibroma, and peripheral giant cell lesion. The present study found 25 cases of inflammatory fibrous hyperplasia, five cases of pyogenic granuloma, two cases of peripheral ossifying fibroma, two cases of giant cell granuloma, and 37 cases of irritation fibroma.

According to the literature, inflammatory fibrous hyperplasia tends to affect older patients and denture wearers, considering that trauma to the edges of the prosthesis would be the etiological factor of this lesion. However, according to Medeiros et al, ${ }^{17}$ fibrous hyperplasia may also present etiological factors, such as diastema, sharp edges, poor hygiene, and iatrogenesis. The present study verified that $36 \%$ of the cases of inflammatory fibrous hyperplasia occurred in patients in the sixth decade of life and $28 \%$ in the seventh decade; the same is true for cases of candidiasis. Individuals with weakened immune systems and the elderly are more likely to present this type of change. According to da Silva et $\mathrm{al}^{18}{ }^{18}$ poor denture hygiene may work as a predisposing factor for candidiasis, which development may also be associated with the patient's systemic conditions. In the present study, $52.77 \%$ of pseudomembranous candidiasis cases found occurred in patients in the seventh decade of life. 
Several oral health conditions are recognized as public health problems due to their prevalence, severity, individual and community impact, costs to the health system, and to the existence of effective prevention and treatment methods. ${ }^{7}$ Thus, it is necessary to mention the group of malignant neoplasms in this study. Seven cases of squamous cell carcinoma, one case of carcinoma in situ, and one case of osteosarcoma were found. Annually, 300,000 new cases of oral cancer are diagnosed all over the world, accounting for almost 130,000 deaths each year and representing a global public health issue ${ }^{19}$ According Saleh et al, ${ }^{20}$ the dentist is responsible for instructing the population on potentially malignant lesions and on the diagnosis of cancerous lesions, which, when done early, increases the chances of cure, patient survival, and improvement of prognosis.

\section{CONCLUSION}

Through the evaluation of the data obtained from the analysis of dental records from FOUPF, between March 2015 and June 2017, several types of oral lesions could be observed, and the most prevalent ones were coated tongue, linea alba, fistula, irritation fibroma, and pseudomembranous candidiasis. The profile of patients assisted at the time of the study predominantly consisted of white women aged 50 through 59 years. The most frequent treatments regarding the lesions diagnosed were surgical treatment, prescription of medications, endodontics, and laser therapy. It is considered that the sample studied presented a significant index of oral lesions/normality changes, whereas $716(22.38 \%)$ patients studied showed some type of change in the oral cavity.

\section{CLINICAL SIGNIFICANCE}

The sample studied presents peculiar characteristics regarding the number of oral lesions/conditions diagnosed. It is also considered that Schools of Dentistry are valuable environments for carrying out epidemiological surveys in stomatology, providing the diagnostic exercise, as long as the students are stimulated for this purpose.

\section{ACKNOWLEDGMENT}

The authors would like to thank the University of Passo Fundo, Rio Grande do Sul, Brazil, for providing a scientific initiation grant through the PIBIC/UPF Program.

\section{REFERENCES}

1. Antunes JL, Narvai PC. Dental health policies in Brazil and their impact on health inequalities. Rev Saúde Públ 2010 Feb;44(2):360-365.

2. Ali MA, Joseph BK, Sundaram D. Dental students' ability to detect and diagnose oral mucosal lesions. J Dent Educ 2015 Feb;79(2):140-145.
3. Roncalli AG, Côrtes MI, Peres KG. Oral health epidemiology and surveillance models in Brazil. Cad Saude Publica 2012 Sep;28(Suppl):S58-S68.

4. Tortorici S, Corrao S, Natoli G, Difalco P. Prevalence and distribution of oral mucosal non-malignant lesions in the western Sicilian population. Minerva Stomatol 2016 Aug;65(4):191-206.

5. Maturana-Ramírez A, Adorno-Farias D, Reyes-Rojas M, Farías-Vergara M, Aitken-Saavedra J. A retrospective analysis of a reactive hyperplastic lesion of the oral cavity: study of 1149 cases diagnosed between 2000 and 2011, Chile. Acta Odontol Latinoam 2015 Aug;28(2):103-107.

6. Jain K, Kaur H. Prevalence of oral lesions and measurement of salivary $\mathrm{pH}$ in the different trimesters of pregnancy. Singapore Med J 2015 Jan;56(1):53-57.

7. Jafarzadeh H, Sanatkhani M, Mohtasham N. Oral pyogenic granuloma: a review. J Oral Sci 2006 Dec;48(4):167-175.

8. Antunes JL, Toporcov TN, Biazevic MG, Boing AF, Bastos JL. Gender and racial inequalities in trends of oral cancer mortality in Sao Paulo, Brazil. Rev Saúde Publ 2013 Jun;47(3):470-478.

9. Borges DM, Sena MF, Ferreira MA, Roncalli AG. Mortality for oral cancer and socioeconomic status in Brazil. Cad Saúde Publ 2009 Feb;25(2):321-327.

10. Cueto A, Martínez R, Niklander S, Deichler J, Barraza A, Esguep A. Prevalence of oral mucosal lesions in an elderly populations in the city of Valparaíso, Chile. Gerodontology 2013 Sep;30(3):201-206.

11. Saintrain MV, Holanda TG, Bezerra TM, Almeida PC. Prevalence of soft tissue oral lesion in elderly and its relations with deleterious habits. Gerodontology 2012 Jun;29(2):130-134.

12. Carvalho Mde V, Iglesias DP, do Nascimento GJ, Sobral AP. Epidemiological study of 534 biopsies of oral mucosa lesions in elderly Brazilian patients. Gerodontology 2011 Jun;28(2):111-115.

13. Peres MA, Antunes JL, Boing AF, Borges KG, Bastos JL. Skin colour is associated with periodontal disease in Brazilian adults: a population-based oral health survey. J Clin Periodontol 2007 Mar;34(3):196-201.

14. Vieira-Andrade RG, Guimarães Fde F, Vieira Cda S, Freire ST, Ramos-Jorge ML, Fernandes AM. Oral mucosa alterations in a socioeconomically deprived region: prevalence and associated factors. Braz Oral Res 2011 Sep-Oct;25(5):393-400.

15. Patil S, Kaswan S, Rahman F, Doni B. Prevalence of tongue lesions in the Indian population. J Clin Exp Dent 2013 Jul;5(3):e128-e132.

16. Henrique PR, Bazaga Júnior M, Araújo VC, Junqueira JLC, Furuse C. Prevalence of changes in oral mucosa in adults in the population of Uberaba, Minas Gerais, Brazil. Rev Gaúcha Odontol 2009 Jul-Sep;57(3):261-267.

17. Medeiros FC, Araújo-Silva TF, Ferreira KA, Oliveira-Moura JM, Cavalcanti-Lima IP, Guerra-Seabra EJ. Use of dental prostheses and their relationship with oral lesions. Rev Salud Publica 2015 Aug;17(4):603-611.

18. da Silva HF, Martins-Filho PR, Piva MR. Denture-related oral mucosal lesions among farmers in a semi-arid Northeastern Region of Brazil. Med Oral Patol Oral Cir Bucal 2011 Sep;6(6):740-744.

19. Petti S, Scully C. Determinants of oral cancer at the national level: just a question of smoking and alcohol drinking prevalence? Odontology 2010 Jul;98(2):144-152.

20. Saleh A, Kong YH, Vengu N, Badrudeen H, Zain RB, Cheonn SC. Dentists' perception of the role they play in early detection of oral cancer. Asian Pac J Cancer Prev 2014 Jan;15(1):229-237. 